\title{
Acute Angle Closure Glaucoma in Unilateral Treated Retinopathy of Prematurity with Asymmetrical Ocular Development
}

\author{
Solehah Jeffrey ${ }^{1}$, Meng Hsien Yong², Wan Haslina Wan Abdul Halim³
}

\begin{abstract}
${ }^{1}$ Trainee, Department of Ophthalmology, Universiti Kebangsaan Malaysia Medical Centre (UKMMC)
Jalan Yaacob Latiff Cheras, Kuala Lumpur. ${ }^{20}$ phthalmologist, Department of Ophthalmology, Universiti Kebangsaan Malaysia Medical Centre (UKMMC) Jalan Yaacob Latiff Cheras, Kuala Lumpur. ${ }^{3}$ Consultant Cornea Surgeon, Department of Ophthalmology, Universiti Kebangsaan Malaysia Medical Centre (UKMMC) Jalan Yaacob Latiff Cheras, Kuala Lumpur.
\end{abstract}

\section{PRESENTATION OF CASE}

A 34-year-old lady with history of retinopathy of prematurity (ROP) presented with five days history of pain and redness in her left eye (OS) which had poor vision from a long time. It was associated with left sided headache and nausea. She had been having left eye pain and left sided headache intermittently for the past one year and the episodes resolved spontaneously.

She was born prematurely at 28 weeks and had laser treatment done in her early neonatal days. She was under ophthalmologist's care until she subsequently defaulted before school-going age. She was on glasses for her right eye (OD) myopia with -5.5DS, and plano lens OS. There was no history of ocular trauma or surgery to either eye.

On examination, the visual acuity was hand movement os and 6/6 OD, with positive relative afferent pupillary defect OS. There was evidence of acute angle closure glaucoma OS with intraocular pressure (IOP) of $52 \mathrm{mmHg}$, shallow anterior chamber and 360-degree closed angle from gonioscopy. Clinically, the lens OS was thick. Fundus OS showed evidence of treated ROP with laser treatment scar up to macula. The optic disc was pale and dragged temporally. Her right eye was normal without evidence of narrow angle, thick lens or previous ROP treatment (Figure 1).

Biometry examinations revealed marked discrepancy between two eyes with axial length and lens thickness of $20.98 \mathrm{~mm}$ and $5.20 \mathrm{~mm}$ OS, compared to $26.03 \mathrm{~mm}$ and $3.80 \mathrm{~mm}$ OD. The anterior chamber depth (ACD) was $2.26 \mathrm{~mm}$ OS and $3.80 \mathrm{~mm}$ OD. Anterior segment OCT showed a narrow angle OS of $24.1^{\circ}$ nasally and $23.7^{\circ}$ temporally with pushing factors from the thick lens (Figure 2).

\section{DIFFERENTIAL DIAGNOSIS}

a. LE phacomorphic glaucoma.

b. LE neovascular glaucoma.

c. LE pupillary block glaucoma with subluxated lens.

\section{CLINICAL DIAGNOSIS}

Left eye AACG secondary to thick lens and short eyeball with history of treated ROP
Corresponding Author:

Wan Haslina Wan Abdul Halim, Universiti Kebangsaan Malaysia Medical Centre (UKMMC) Jalan Yaacob Latiff,

Cheras-56000, Kuala Lumpur.

E-mail:yongmenghsien@gmail.com afifiyad@yahoo.co.uk

DOI: $10.14260 /$ jemds $/ 2019 / 689$

Financial or Other Competing Interests: None.

How to Cite This Article:

Jeffrey S, Yong MH, Halim WHWA. Acute angle closure glaucoma in unilateral treated retinopathy of prematurity with asymmetrical ocular development. J. Evolution Med. Dent. Sci. 2019;8(42):31793181, DOI: 10.14260/jemds/2019/689

Submission 09-08-2019,

Peer Review 30-09-2019,

Acceptance 08-10-2019,

Published 21-10-2019. 


\section{PATHOLOGICAL DISCUSSION}

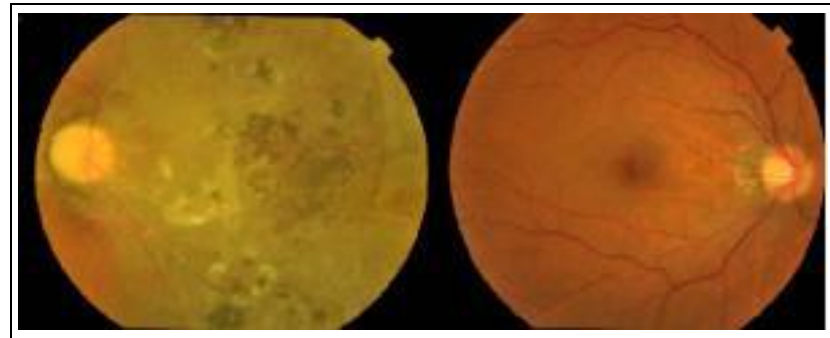

Figure 1. Fundus Photo OS Showed Evidence of Treated ROP. Fundus Photo OD was Normal

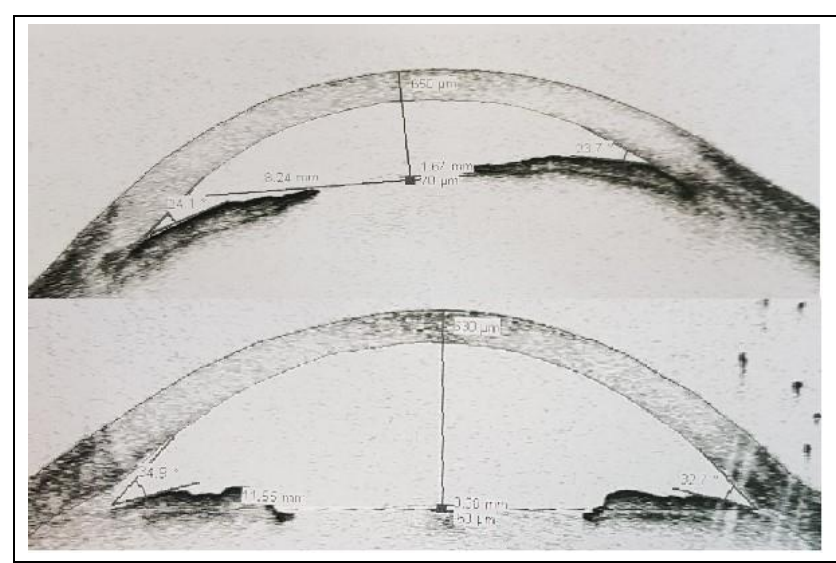

Figure 2. Anterior Segment OCT OS (Up) Showed Narrowed Angle and Shallow AC, as Compared to Normal OD (Down)

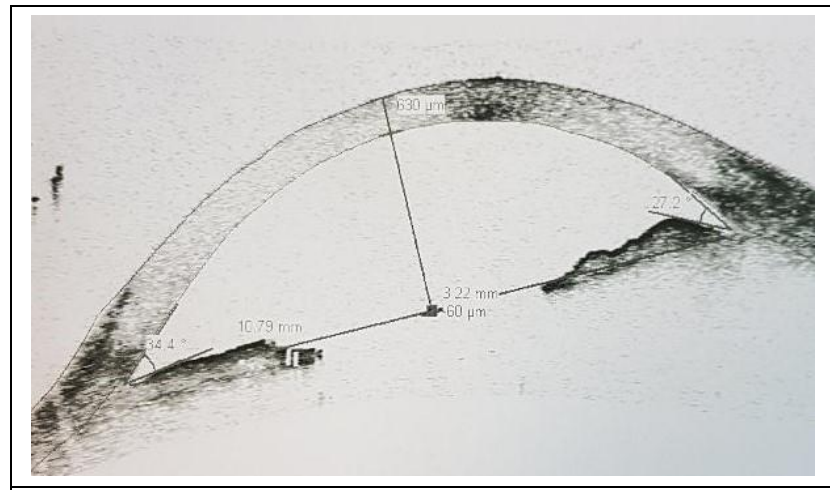

Figure 3. Anterior Segment OCT OS Post Lens Aspiration with IOL Implantation

Retinopathy of prematurity (ROP) is an eye disease in premature infants characterized by a delay in physiologic retinal vascular development followed by abnormal vascular proliferation into the vitreous. ${ }^{1}$ Besides ROP, eyes of premature infants have shorter axial lengths, shallower anterior chamber and more highly curved cornea than eyes of full-term infants and these differences increases as the severity of ROP increases. ${ }^{2}$ The proposed mechanism of this anatomical abnormalities has not been well explained, but there is theory suggests that the early effect of growth restriction associated with ROP is followed later by a deregulation of ocular growth within the posterior segment. ${ }^{2}$ Another theory mentions that the ROP lesion may exert a mechanical effect on the anterior sclera and anterior segment, being situated in the part of the eye undergoing maximum growth during late foetal and early neonatal life. ${ }^{3}$
Unilateral treated ROP is relatively rare with incidence of $4.2 \%$ as compared to bilateral cases $(34.7 \%) .{ }^{4}$ In view of the anatomical abnormalities corresponded to the severity of ROP as mentioned earlier, patients with unilateral treated ROP will have discrepancy of the anatomy between two eyes. This discrepancy will predispose patients to unilateral complications that related to ROP. Our patient presented with a short eyeball and thickened lens in her unilateral treated ROP eye that eventually led her to development of late onset unilateral acute angle closure glaucoma.

Angle closure glaucoma in ROP usually develops in the childhood period due to shallowing of the anterior chamber and narrowing of the angle, which leads to angle closure. Secondary glaucoma also results from neovascularization. To the best of our knowledge there are seven previously reported cases of late onset AACG in adults with treated ROP.5,6,7,8 Out of the seven cases, only one was possible unilateral case of treated ROP (Fellow eye 20/25), while the other six cases are bilateral treated ROP. Lens factor (Thick lens) was reported as the contributing factor in one case, ${ }^{6}$ while others were due to cicatricial ROP, pupillary block, and neovascular causes.

\section{DISCUSSION OF MANAGEMENT}

She was treated with IOP lowering agents and had a lens aspiration with intraocular lens (IOL) implantation done one week after her initial presentation. Post operatively, her IOP returns to normal with improvement of vision to $2 / 60$ OS. Anterior segment OCT showed the angle improved to $34.4^{\circ}$ nasally and $27.2^{\circ}$ temporally with increase in ACD (Figure 3).

Treatment for adult patients with ROP related late onset AACG depends on the causes. Michael et al proposed that in the late onset AACG without intumescent lens, the treatment would be peripheral iridectomy and observation if the IOP remains well controlled. If the IOP remains high in this group of patients, trabeculectomy or ciliodestruction should be performed depending on the visual prognosis. ${ }^{8}$ On the other hand, lens extraction should be offered for patients with intumescent cataract. In this case, lens aspiration was done in our patient as she had a thickened lens that contributed to the AACG. The surgery was able to bring back the IOP to normal level without the need of anti-glaucoma, with widened anterior chamber and angle. Her vision was improved despite of the pre-existing amblyopia.

Anatomical abnormalities in the eye of treated ROP that persist into adulthood predispose patient to angle closure glaucoma. Unilateral cases, despite of its rarity, provide a clear cause-effect relationship of the pathology with the anatomical discrepancy between two eyes. Lens aspiration should be considered for treated ROP eye with late onset AACG and thick lens.

\section{FINAL DIAGNOSIS}

Left eye AACG secondary to thick lens and short eyeball with history of treated ROP. 


\section{REFERENCES}

[1] Suelves AM, Shulman JP. Current screening and treatments in retinopathy of prematurity in the US. Eye Brain 2016;8:37-43.

[2] Cook A, White S, Batterbury M, et al. Ocular growth and refractive error development in premature infants with or without retinopathy of prematurity. Invest Ophthalmol Vis Sci 2008;49(12):5199-207.

[3] Fielder AR, Quinn GE. Myopia of prematurity: nature, nurture or disease? Br J Ophthalmol 1997;81(1):2-3.

[4] Wani VB, Kumar N, Sabti K, et al. Results of screening for retinopathy of prematurity in a large nursery in Kuwait: Incidence and risk factors. Indian $\mathrm{J}$ Ophthalmol 2010;58(3):204-8.
[5] Kushner BJ. Ciliary block glaucoma in retinopathy of prematurity. Arch Ophthalmol 1982;100(7):1078-9.

[6] Ueda N, Ogino N. Angle-closure glaucoma with pupillary block mechanism in cicatricial retinopathy of prematurity. Ophthalmologica 1988;196(1):15-8.

[7] Smith J, Shivitz I. Angle-closure glaucoma in adults with cicatricial retinopathy of prematurity. Arch Ophthalmol 1984;102(3):371-2.

[8] Michael AJ, Pesin SR, Katz LJ, el al. Management of lateonset angle-closure glaucoma associated with retinopathy of prematurity. Ophthalmology 1991; 98(7):1093-8. 